\title{
Could Reducing Body Fatness Reduce the Risk of Aggressive Prostate Cancer via the Insulin Signalling Pathway? A Systematic Review of the Mechanistic Pathway
}

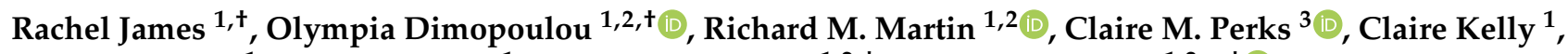 \\ Louise Mathias ${ }^{1}$, Stefan Brugger ${ }^{1}$, Julian P. T. Higgins ${ }^{1,2, \ddagger}$ and Sarah J. Lewis $1,2, *, \ddagger(\mathbb{D}$ \\ 1 Department of Population Health Sciences, Bristol Medical School, University of Bristol, Bristol BS8 2BN, UK \\ rachel_symes@hotmail.co.uk (R.J.); Olympia.Dimopoulou@bristol.ac.uk (O.D.); \\ richard.martin@bristol.ac.uk (R.M.M.); Claire.Kelly@bristol.ac.uk (C.K.); Louisemathias@hotmail.com (L.M.); \\ Stefan.Brugger@bristol.ac.uk (S.B.); Julian.Higgins@bristol.ac.uk (J.P.T.H.) \\ 2 Medical Research Council Integrative Epidemiology Unit, University of Bristol, Bristol BS8 2BN, UK \\ 3 IGF \& Metabolic Endocrinology Group, Translational Health Sciences, Bristol Medical School, \\ University of Bristol, Bristol BS10 5NB, UK; claire.m.perks@bristol.ac.uk \\ * Correspondence: s.j.lewis@bristol.ac.uk \\ + These authors contributed equally. \\ $\ddagger$ These authors contributed equally.
}

Citation: James, R.; Dimopoulou, O.; Martin, R.M.; Perks, C.M.; Kelly, C.; Mathias, L.; Brugger, S.; Higgins, J.P.T.; Lewis, S.J. Could Reducing Body Fatness Reduce the Risk of Aggressive Prostate Cancer via the Insulin Signalling Pathway? A Systematic Review of the Mechanistic Pathway. Metabolites 2021, 11, 726. https://doi.org/10.3390/metabo 11110726

Academic Editor: Anna Floegel

Received: 24 September 2021

Accepted: 19 October 2021

Published: 23 October 2021

Publisher's Note: MDPI stays neutral with regard to jurisdictional claims in published maps and institutional affiliations.

Copyright: (c) 2021 by the authors. Licensee MDPI, Basel, Switzerland. This article is an open access article distributed under the terms and conditions of the Creative Commons Attribution (CC BY) license (https:// creativecommons.org/licenses/by/ $4.0 /)$.
Abstract: Excess body weight is thought to increase the risk of aggressive prostate cancer (PCa), although the biological mechanism is currently unclear. Body fatness is positively associated with a diminished cellular response to insulin and biomarkers of insulin signalling have been positively associated with PCa risk. We carried out a two-pronged systematic review of (a) the effect of reducing body fatness on insulin biomarker levels and (b) the effect of insulin biomarkers on PCa risk, to determine whether a reduction in body fatness could reduce PCa risk via effects on the insulin signalling pathway. We identified seven eligible randomised controlled trials of interventions designed to reduce body fatness which measured insulin biomarkers as an outcome, and six eligible prospective observational studies of insulin biomarkers and PCa risk. We found some evidence that a reduction in body fatness improved insulin sensitivity although our confidence in this evidence was low based on GRADE (Grading of Recommendations, Assessment, Development and Evaluations). We were unable to reach any conclusions on the effect of insulin sensitivity on PCa risk from the few studies included in our systematic review. A reduction in body fatness may reduce PCa risk via insulin signalling, but more high-quality evidence is needed before any conclusions can be reached regarding $\mathrm{PCa}$.

Keywords: body fatness; prostate cancer; biomarker; insulin; insulin signalling; mechanisms; systematic review

\section{Introduction}

Prostate cancer $(\mathrm{PCa})$ is the leading cause of morbidity and mortality in men worldwide [1]. In 2018, there were 1.28 million newly diagnosed PCas, making the disease the second most commonly occurring cancer in men [2]. Despite the importance of the disease, little is understood about the causes of PCa. Established risk factors of the disease-age, race and family history [3] - are not modifiable and, therefore, a principal focus of current research is to advance our understanding of modifiable risk factors.

Excess body weight, resulting from imbalances in diet and physical activity, has been implicated as a risk factor for the incidence and progression of several cancers including PCa [4,5]. In 2012, overweight and obesity, characterised by excess body fat, w estimated to contribute to $3.9 \%$ of all incident cancers, a figure expected to rise in the next few decades given current trends in this risk factor [6]. Whilst the association with localised PCa remains 
inconsistent, evidence has shown that body fatness is positively associated with aggressive PCa, PCa recurrence and survival [7-9]. In a meta-analysis of 31 cohort and 25 case-control studies, a higher body mass index (BMI) was associated with a greater risk of PCa (overall relative risk (RR): 1.05 per $5 \mathrm{~kg} / \mathrm{m}^{2}$ increment; $95 \%$ confidence interval (CI) 1.01-1.08). In the same study, the relative risk was stronger for advanced (RR 1.12 per $5 \mathrm{~kg} / \mathrm{m}^{2}$ increment 95\% CI 1.01-1.23) PCa and weaker and inverse for localised PCa (RR 0.96 per $5 \mathrm{~kg} / \mathrm{m}^{2}$ increment, 95\% CI 0.89-1.03) compared with controls [10].

With the increasing worldwide prevalence of overweight and obesity in men [11], a better understanding of the molecular mechanisms that underpin the relationship between excess body fatness and PCa is warranted. Understanding such mechanisms may help to promote preventative lifestyle strategies to reduce the incidence and progression of PCa and may highlight targets for intervention, treatment and risk monitoring [12].

Insulin is a hormone made and secreted by the pancreas that plays a key role in the regulation of blood glucose levels. Insulin binds to receptors on cell membranes, initiating a cascade of reactions that activate specific signalling pathways within the cell. This results in cellular uptake of glucose, promoting cell growth and inhibiting apoptosis [13].

Body fatness is positively associated with increasing blood insulin levels [14-16], causing a diminished cellular response to insulin termed insulin resistance. The reduced cellular response to insulin mainly occurs in insulin-target tissues, such as muscle, fat and liver. Cancer cells do not become insulin resistant, insulin resistance leads to the body producing more insulin to compensate, which, combined with an overexpression of insulin receptors on cancer cells, may lead to the promotion of cancer initiation and progression [17]. Insulin resistance is common among overweight and obese individuals and leads to hyperinsulinemia, where insulin levels are chronically elevated relative to blood glucose. In some cases, insulin resistance leads to the development of type 2 diabetes mellitus (T2DM), a metabolic disease that is positively associated with body fatness [18-20].

Evidence suggests that insulin and biomarkers of higher circulating insulin, including C-peptide, are positively associated with PCa risk [21]. A diagnosis of T2DM, however, seems to be protective $[22,23]$, which may be due to the potential anti-neoplastic biological effects of diabetic medications, such as metformin [24]. Alteration of the insulin signalling pathway is therefore a plausible mechanism underlying the link between body fatness and PCa.

Whilst there is evidence that excess body fatness is a risk factor for aggressive PCa [10], it is not clear whether reducing body fatness will reduce cancer progression, and whether it does this via effects on insulin sensitivity. Follow-up periods for studies examining interventions aiming to reduce body fatness are insufficiently long to assess the impact on prostate cancer diagnoses [15]. Recently, an International Agency for Research on Cancer (IARC) working group produced a framework to assess evidence for the effect of interventions on cancer risk for their cancer prevention handbooks. The framework uses a two-step approach, where two different sets of studies are combined: studies in set 1 examine the effect of the intervention on a mechanistic intermediate and set 2 examines the same intermediate with respect to cancer risk [25]. This is a similar approach to the one we took when developing the World Cancer Research Fund (WCRF)/Bristol Methodology to assess the mechanism between an exposure and cancer risk [12]. In this methodology the first stage is designed to identify mechanisms underpinning a specific exposure-disease relationship and prioritise these mechanisms using specifically designed text mining tools. The second stage is a targeted systematic review of studies of the exposure of interest and intermediate phenotypes relating to the mechanism of interest, and a separate systematic review of studies of the same intermediate phenotypes and outcome of interest. In this systematic review, we used the second stage of this methodology [12] to assess the evidence for: (1) the effect of intervening to reduce body fatness on biomarkers in the insulin signalling pathway; and (2) the effect of biomarkers in the insuling signalling pathway on prostate cancer risk. 


\section{Material and Methods}

\subsection{PICO Questions}

Our objective was to systematically review and synthesise evidence from studies investigating whether changing body fatness might impact on PCa risk via the insulin signalling pathway; in doing so, we investigated the insulin signalling pathway as a potential mechanistic link between body fatness and PCa incidence or progression.

Relevant studies which contributed evidence for mechanistic links were those that reported an intermediate phenotype (here the insulin signalling pathway) as either an outcome or an exposure. Defined using PICO/PECO (population, intervention/exposure, control, and outcomes), we separately identified studies which assessed: (1) the effects of dietary interventions (I) to reduce body fatness in adult males $(\mathrm{P})$ on insulin outcomes (O) compared to controls (C); and (2) whether insulin signalling (I/E) in adult males (P) impacted on PCa outcomes (O) compared to controls (C). Our interest was primarily in humans so we prioritised studies in humans and a priori decided to only review animal studies where the former were absent.

\subsection{Standards of Reporting}

This systematic review and meta-analysis followed the WCRF International/University of Bristol methodological framework [12]. The review was registered in the PROSPERO International Prospective Register of Systematic Reviews (CRD42020196064) and reported according to the Preferred Reporting Items for Systematic review and Meta-Analysis Protocols (PRISMA-P) checklist. As all analyses were based on the published results of previous studies, no ethical approvals or patient consent were required.

\subsection{Inclusion and Exclusion Criteria}

\subsubsection{Body Fatness-Insulin Signalling-Specific Criteria}

We included experimental studies examining the effects of dietary intake interventions to change body fatness on the insulin signalling pathway. We excluded studies where the only intervention had a physical activity component, as physical activity is likely to have an independent effect on insulin signalling. Randomised controlled trials (RCTs) with human adult participants were eligible for inclusion, with no restriction on race or nationality. Since only males can develop prostate cancer, we only included studies with male subjects analysed separately. Studies which included a high proportion of participants with a diagnosis of type 1 or $2 \mathrm{DM}$ at baseline were excluded, although we included population-based studies which did not exclude participants on the basis of diabetes.

Our exposure of interest was a change in body fatness measured by indirect methods including anthropometric biomarkers (BMI, waist circumference, waist-to-hip ratio (WHR), crude weight and skinfold thickness) and bioelectrical impedance analysis (BIA), or direct methods including densitometry, computed X-ray tomography (CT), magnetic resonance imaging (MRI), and dual-energy X-ray absorptiometry (DXA).

Outcomes of interest were serum or plasma insulin or biomarkers and surrogate indices of the insulin signalling pathway and insulin resistance (fasting glucose, C-peptide, pro-insulin, homeostatic model assessment for insulin resistance (HOMA-IR), homeostatic model assessment for insulin sensitivity (HOMA-S), glycated hemoglobin (HbA1c) and quantitative insulin sensitivity check index (QUICKI)).

\subsubsection{Insulin Signalling-PCa-Specific Criteria}

We included studies examining the association between the insulin signalling pathway and PCa outcomes. Only RCTs or prospective observational studies were eligible. To reduce the possibility of the results being affected by reverse causation we only included studies in which exposure was measured at least two years (or with a study mean/median of at least 5 years) before outcomes were counted. Cross-sectional and retrospective study 
designs were excluded. Commentaries, editorials and conference proceedings and studies published only as protocols were excluded.

Studies of human adult males (aged 18 years or over) with no restriction on race or nationality were eligible for inclusion. Men with a PCa diagnosis at baseline were excluded, with the exception of studies examining cancer progression as the outcome. Within such studies, men undergoing androgen deprivation therapy (ADT) for PCa were excluded. ADT increases the risk of insulin resistance and diabetes in this population [26]; by excluding men receiving ADT we aimed to specifically study the effect of dysregulation of the insulin signalling pathway due to excess body fatness on PCa. Studies which had a high proportion of participants with a DM diagnosis at baseline were also excluded, although we did not exclude population-based studies which may have included some men with DM. Figure S1 shows the inclusion/exclusion process we implemented for potentially eligible studies.

Exposures of interest were serum or plasma insulin or biomarkers and surrogate indices of the insulin signalling pathway and insulin resistance (fasting glucose, C-peptide, pro-insulin, HOMA-IR, HOMA-S and HbA1c).

Our outcomes of interest were PCa incidence, measures of progression (Gleason score increase, biochemical recurrence, development of local and distant metastases, change in tumour stage and decrease in number of positive cores) and PCa-specific mortality. We included any stage of cancer but investigated incident cancer and cancer progression separately. Among the included studies, a broad range of PCa definitions was reported. For the assessment of the insulin-PCa association, a set of 7 broader categories was adopted instead (see Table S7 for details).

\subsection{Data Collection and Analysis}

\subsubsection{Search Methods}

We carried out two separate searches to identify studies examining: (i) effects of changes to body fatness on insulin signalling; and (ii) associations between biomarkers of insulin signalling and PCa outcomes. Searches were conducted using the Cochrane Database of Systematic Reviews (The Cochrane Library, July 2020; MEDLINE Ovid (from 1946 to July 2020); Embase Ovid (1980 to July 2020); and BIOSIS (1969 to July 2020). The search strategy comprised MeSH terms, text words and keywords. Full search terms that were implemented in MEDLINE, EMBASE and BIOSIS are shown in the supplementary material. Study design search filters for systematic reviews, RCTs and eligible observational studies were applied as necessary. Amendments to the search strategy were made to reflect individual database requirements. No date or language restrictions were applied. A manual search of the grey literature (Opengrey.eu (http:/ / opengrey.eu/, accessed on 18 October 2021); Clinicaltrials.gov (https:/ / clinicaltrials.gov/, accessed on 18 October 2021); PROSPERO (https:/ / www.crd.york.ac.uk/PROSPERO/, accessed on 18 October 2021) was also conducted in May 2020 to source additional papers not returned in the search. Results from the literature searches were imported into Endnote X9, where duplicates were identified and removed using the Endnote function.

\subsubsection{Identification and Selection of Studies}

We used a sequential approach to the identification and selection of studies, in terms of both the source of the studies and the types of studies (for further details, please see supplementary material).

Three reviewers (RJ, CK and LM) independently screened titles and abstracts of studies for possible inclusion against the inclusion criteria. If a title or abstract met the eligibility criteria, or eligibility could not be determined, a full-text version of the article was obtained and independently screened by two of three reviewers (RJ, CK and OD). Discrepancies between reviewers were resolved via discussion until a consensus was reached. 


\subsubsection{Data Extraction and Management}

Following the screening process, data from the eligible primary studies were independently extracted by two of three reviewers (OD, SL, SB) using a predefined data extraction form. Disagreements from this process were resolved through discussion. Data extracted for all study types included publication details (article title, year, study location), study characteristics (study design, sample size, participant demographics), intervention or exposure (setting, intervention description, how exposures measured), outcomes of interest and results (mean difference, standard deviation, $p$ value, odds ratio, 95\% confidence intervals). For studies of body fatness-insulin sensitivity association, we also extracted details of the intervention and the control and baseline adiposity and, within group prepost-intervention mean differences in insulin biomarker levels; where this was not reported we calculated this ourselves as outlined in the supplementary material. For studies of insulin sensitivity- prostate cancer outcomes, we extracted information on any potential confounding factors which were adjusted for in the analysis.

\subsubsection{Data/Statistical Analysis}

The synthesis of data was conducted separately for the two sides of the pathway. Extracted data from the included primary studies were tabulated to summarise key characteristics. We converted fasting glucose to $1 \mathrm{mmol} / \mathrm{L}$ and fasting insulin to $1 \mu \mathrm{U} / \mathrm{mL}$ units where these units were not already presented as such (details on the conversion factors we used are in the supplementary material).

Where we had at least 3 sufficiently similar studies (same exposures and outcomes), we performed meta-analysis of results from included studies to estimate a summary measure of effect. Both fixed-effect models and random-effects models were applied to compute pooled standardised mean difference (SMD) and relative risk (RR), with the intention of focusing on the random-effects results unless there was evidence that the model was unsuitable (e.g., evidence of small study effects which could be due to publication bias).

Results were reported and graphically displayed using forest plots where we had at least 2 studies which measured the same exposure and outcome, and which provided data in a format that allowed them to be combined. Heterogeneity in effect size between studies was assessed by estimating the between-study variance in effect sizes $\left(\tau^{2}\right)$. Small study effects were assessed visually using funnel plots and tested statistically using an Egger test [27]. Where meta-analysis was not possible, results for individual studies were tabulated, data were graphically displayed using Albatross plots which are scatter plots of study sample sizes against 2-sided $p$ values, allowing comparison of the direction of effect and strength of evidence across studies even when there is some heterogeneity in the exposure and outcome [28]. We also provided narrative summaries of the relevant results.

\subsubsection{Subgroup Analyses}

For associations of body fatness with circulating insulin, we analysed studies separately according to whether the trial intervention resulted in a greater reduction in body fatness in the intervention group compared to the control group.

We also analysed studies separately by type of insulin biomarker and according to whether the PCa outcome was localised or advanced disease. We defined advanced $\mathrm{PCa}$ as one that had spread either to the pelvis, lymph nodes, or surrounding organs (locally advanced PCa) or PCa that had spread to more distant organs (distant metastases). High-grade PCa was defined as having a Gleason score of greater than or equal to 7 and low-grade PCa as a score less than 7. Supplementary Table S1 provides details of outcome definitions by study. 


\subsection{Assessment of Methodological Quality of Included Studies}

\section{Risk of Bias of Included Studies}

We included two main types of study designs within the review-RCTs and observational studies and we assessed risk of bias using selected up-to-date tools for either RCTs or non-randomised studies of exposures. We used the revised Cochrane risk-of-bias tool (RoB 2) to evaluate the risk of bias in RCTs [29]. The tool contains 5 domains, namely biases arising from: the randomisation process; deviations from intended interventions; missing outcome data; measurement of the outcome; selection of the reported result. Each study was assigned domain-level judgements and an overall judgement of risk assessed as either 'low risk of bias', 'some concerns' or 'high risk of bias'.

For non-randomised studies of exposures, we used a preliminary version of the Risk of Bias in Non-randomised studies of Exposures (ROBINS-E) tool. Similar to ROBINS-I, bias is assessed across 7 domains, bias due to: confounding; measurement of exposure; selection of participants into the study; post-exposure interventions; missing data; measurement of outcomes; and selection of the reported result. Judgements of risk of bias are categorised as 'low risk', 'low risk except for concerns of uncontrolled confounding', 'some concerns', 'high risk' or 'very high risk'. Results assessed to be at high' or 'very high' risk of bias were excluded from syntheses.

In our inclusion criteria, we prespecified age and BMI as important confounders of the insulin-prostate cancer association and did not include studies unless they had adjusted for these confounders. Other important confounders for the insulin-PCa association were ethnicity, family history of $\mathrm{PCa}$, history of cancer diagnosis (aside from nonmelanoma skin cancer), height and insulin-like growth factor (IGF) and these were used to assess risk of bias due to confounding.

Risk-of-bias assessments were performed independently by two reviewers (OD and SL), with any discrepancies resolved by discussion until a consensus was reached. An overall risk-of-bias judgement was assigned to each included study and assessments are presented in summary tables for each study.

\subsection{Overall Assessment of the Strength of the Evidence: GRADE}

The certainty in the evidence from in the included studies was rated using the GRADE framework [30], informed by the risk-of-bias status of the included studies, imprecision, heterogeneity, indirectness and reporting bias. All results started at the highest GRADE level, whether RCTs or observational studies [31]. An overall GRADE rating of high, moderate, low or very low certainty was assigned to each summary result. The assessments GRADE quality were determined by four reviewers (OD, SL, RM, JH) through discussion until a consensus was reached

\section{Results}

Our searches identified 15,478 potentially eligible studies of body fatness and insulin signalling. After removing duplicates and screening studies for eligibility, we identified seven eligible studies [32-38] where a reduction in body fatness was the exposure and at least one biomarker of insulin sensitivity was reported as an outcome (Figure 1).

We identified 3152 potentially eligible studies on insulin sensitivity and prostate cancer but only six of these studies (Figure 2) met our inclusion criteria [39-44].

\subsection{Body Fatness-Insulin Association Studies}

Table 1 shows the characteristics of the included studies for the body fatness-insulin association [32-38]. All seven eligible studies were RCTs carried out in men only, the largest of which had 80 participants and the smallest only 22 participants. The studies were carried out in Canada, Malaysia, Australia, USA, Netherlands, China, Brazil and Spain, among men with a mean age of 29 to 61. One study [32] had two separate interventions and one control group. The interventions were heterogeneous across studies but focussed on either calorie reduction or intermittent fasting. 


\section{PRISMA Flow Diagram Body fatness - Insulin}

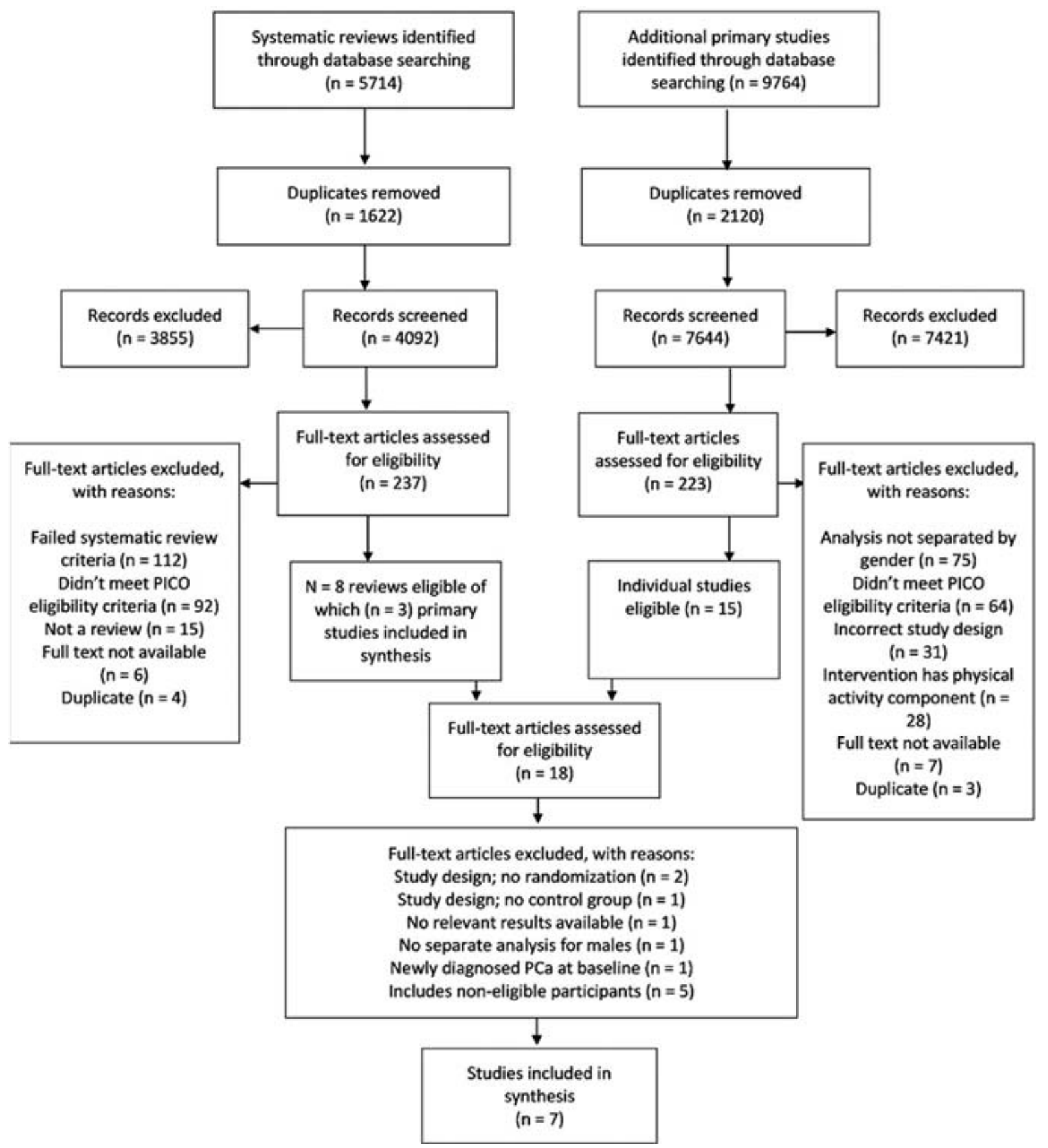

Figure 1. Flow diagram of body fatness-insulin association studies identified and included. 


\section{PRISMA Flow Diagram Insulin - Prostate cancer}

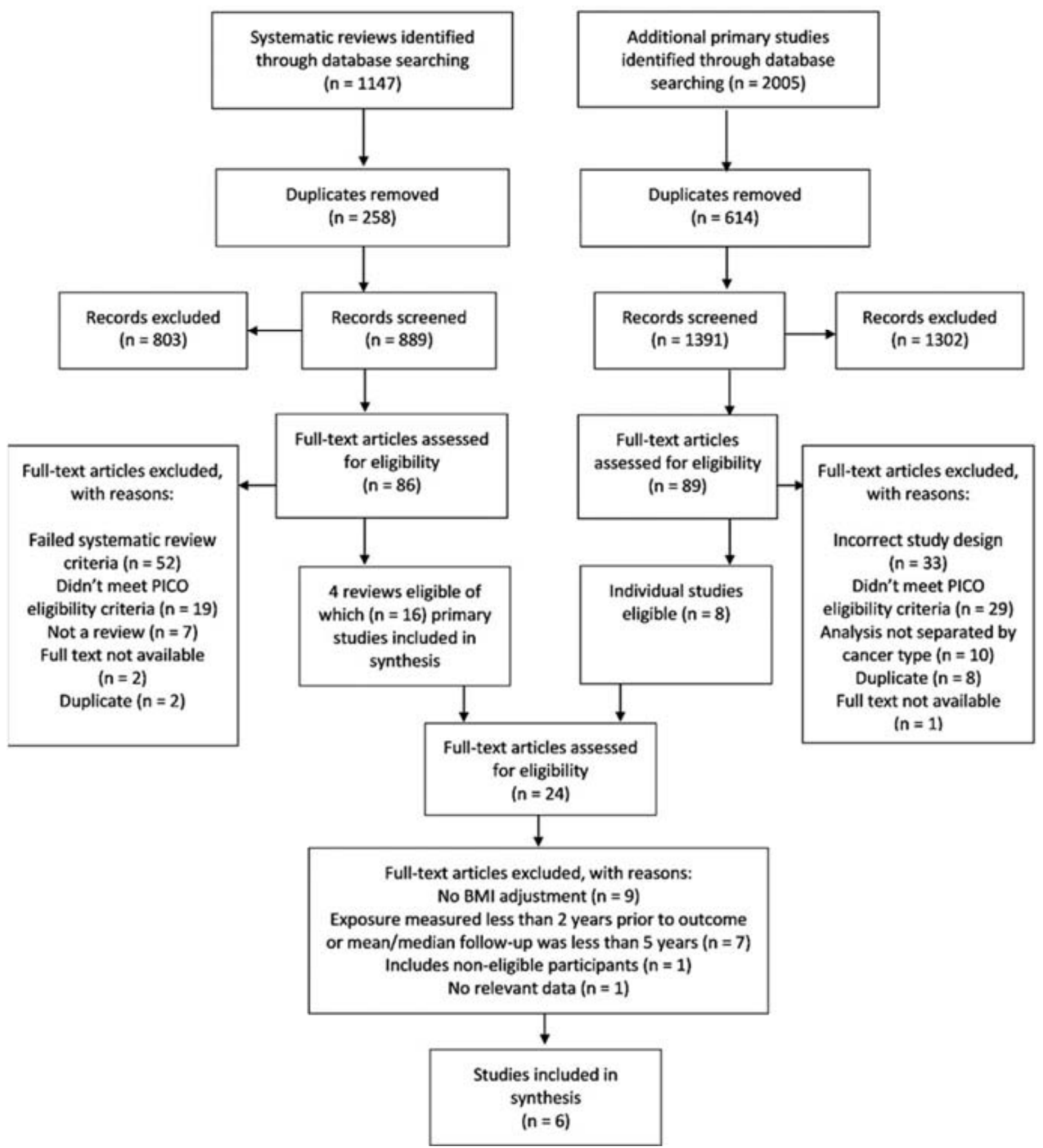

Figure 2. Flow diagram of insulin-prostate cancer association studies identified and included. 
Table 1. Characteristics of included body fatness-insulin association studies.

\begin{tabular}{|c|c|c|c|c|c|c|c|c|}
\hline $\begin{array}{l}\text { Author } \\
\text { (Date) }\end{array}$ & $\begin{array}{c}\text { Country of } \\
\text { Origin }\end{array}$ & Adiposity Status $^{1}$ & Ethnicity & $\begin{array}{c}\text { Number of } \\
\text { Participants: } \\
\text { (Intervention/ Control) }\end{array}$ & $\begin{array}{l}\text { Age of } \\
\text { Participants } \\
\text { (Intervention/ } \\
\text { Control) }\end{array}$ & Intervention Group & Control Group & Outcome Measured \\
\hline \multirow{8}{*}{$\begin{array}{l}\text { Ross R } \\
(2000)\end{array}$} & \multirow{8}{*}{ Canada } & \multirow{8}{*}{$\begin{array}{l}\text { Obese men-BMI } \\
>27 \mathrm{~kg} / \mathrm{m}^{2}\end{array}$} & \multirow{8}{*}{ NA } & \multirow{8}{*}{$22(14 / 8)$} & \multirow{8}{*}{$\begin{array}{l}42.6(9.7) / \\
46.0(10.9)\end{array}$} & \multicolumn{2}{|c|}{ Baseline period: Weight maintenance diet (4-5 weeks) } & Fasting glucose \\
\hline & & & & & & \multirow{6}{*}{$\begin{array}{l}\text { Diet-induced weight loss group: } \\
\text { Reduction in isocaloric diet by } 700 \mathrm{kcal} / \mathrm{d} \text { to } \\
\text { achieve a weight loss of } 0.6 \mathrm{~kg} / \text { week. } \\
\text { Free-living participants (self-selected foods. } \\
\text { Weekly } 1 \mathrm{~h} \text { seminars with dietitian. } \\
\text { Participants kept daily food records, } \\
\text { reviewed by the dietitian. }\end{array}$} & \multirow{6}{*}{$\begin{array}{l}\text { Body weight maintenance group: } \\
\text { Participants asked to maintain their body } \\
\text { weight throughout the study period. } \\
\text { Free-living participants (self-selected } \\
\text { foods. Weekly } 1 \mathrm{~h} \text { seminars with dietitian. } \\
\text { Participants kept daily food records, } \\
\text { reviewed by the dietitian. }\end{array}$} & Fasting insulin \\
\hline & & & & & & & & OGTT glucose $(2 \mathrm{~h})$ \\
\hline & & & & & & & & OGTT insulin (2 h) \\
\hline & & & & & & & & Glucose disposal rate \\
\hline & & & & & & & & $\begin{array}{l}\text { Glucose disposal } \\
\text { (Oxidative fraction) }\end{array}$ \\
\hline & & & & & & & & $\begin{array}{l}\text { Glucose disposal } \\
\text { (noxidative fraction }\end{array}$ \\
\hline & & & & & & \multicolumn{2}{|c|}{ Intervention period: 12 weeks } & \\
\hline \multirow{3}{*}{$\begin{array}{l}\text { Teng NIMF } \\
\text { (2013) }\end{array}$} & \multirow{3}{*}{ Malaysia } & \multirow{3}{*}{$\begin{array}{l}\text { BMI: } 23.0-29.9 \mathrm{~kg} / \mathrm{m}^{2} ; \\
\text { range }\end{array}$} & \multirow{3}{*}{ Malay } & \multirow{3}{*}{$56(28 / 28)$} & \multirow{3}{*}{$\begin{array}{l}59.6(5.4) / \\
59.1(6.2)\end{array}$} & $\begin{array}{l}\text { Baseline period: No, but eligible subjects shou } \\
\text { or have changed their dietary patt }\end{array}$ & $\begin{array}{l}\text { A not have practiced Muslim Sunnah fasting } \\
\text { n three months before the study. }\end{array}$ & \multirow{3}{*}{ Fasting glucose } \\
\hline & & & & & & $\begin{array}{l}\text { Fasting calorie restriction (FCR) group: } \\
\text { Reduction of 300-500 kcal/d combined with } \\
2 \text { days/ week of Muslim Sunnah Fasting. } \\
\text { During fasting day: a light meal before } \\
\text { sunrise (Sahur), no food and drink during } \\
\text { the day (approximately for } 13 \mathrm{~h} \text { ) and a } \\
\text { complete meal after sunset (Iftar). Subjects } \\
\text { provided with seven-day food menu } \\
\text { guidelines. Weekly telephone-call to obtain } \\
\text { information regarding subjects' dietary } \\
\text { intake and to ensure compliance. Fasting log } \\
\text { book and food diaries were provided during } \\
\text { each assessment meeting. }\end{array}$ & $\begin{array}{l}\text { Maintenance group: } \\
\text { Participants were asked to maintain their } \\
\text { present lifestyle. }\end{array}$ & \\
\hline & & & & & & Intervention pe & od: 12 weeks & \\
\hline \multirow{3}{*}{$\begin{array}{l}\text { Pritchard J } \\
\quad(2002)\end{array}$} & \multirow{3}{*}{ Australia } & \multirow{3}{*}{$\begin{array}{l}\text { Overweight men-BMI: } \\
29.0(2.6) \mathrm{kg} / \mathrm{m}^{2} \\
\text { mean }(\mathrm{SD})\end{array}$} & \multirow{3}{*}{ Australian } & \multirow{3}{*}{$\begin{array}{c}24[12(10 \text { available at } \\
\text { baseline)/12 }(2 \\
\text { available at baseline })]\end{array}$} & & Baseline $\mathrm{p}$ & riod: No & \multirow{3}{*}{ Fasting insulin } \\
\hline & & & & & $\begin{array}{l}43.4(5.7) / \\
43.4(5.7)\end{array}$ & $\begin{array}{l}\text { Low-fat (25\% of dietary energy) diet group: } \\
\text { The intervention was personalised according } \\
\text { to the subject's usual dietary pattern and } \\
\text { using the National Heart Foundation } \\
\text { booklet, The Weight Loss Guide. } \\
\text { Compliance was monitored from food } \\
\text { diaries and measurement of weight at } \\
\text { monthly sessions. }\end{array}$ & $\begin{array}{l}\text { Maintenance group: } \\
\text { Participants were instructed to maintain } \\
\text { their pre-study dietary and activity } \\
\text { patterns, monitored at monthly } \\
\text { measurement sessions similar to those of } \\
\text { the intervention group. }\end{array}$ & \\
\hline & & & & & & \multicolumn{2}{|c|}{ Intervention period: 48 weeks } & \\
\hline
\end{tabular}


Table 1. Cont.

\begin{tabular}{|c|c|c|c|c|c|c|c|c|}
\hline $\begin{array}{l}\text { Author } \\
\text { (Date) }\end{array}$ & $\begin{array}{l}\text { Country of } \\
\text { Origin }\end{array}$ & Adiposity Status ${ }^{1}$ & Ethnicity & $\begin{array}{c}\text { Number of } \\
\text { Participants: } \\
\text { (Intervention/ Control) }\end{array}$ & $\begin{array}{c}\text { Age of } \\
\text { Participants } \\
\text { (Intervention/ } \\
\text { Control) }\end{array}$ & Intervention Group & Control Group & Outcome Measured \\
\hline \multirow{4}{*}{$\begin{array}{l}\text { Katzel LI } \\
(1995)\end{array}$} & \multirow{4}{*}{ USA } & \multirow{4}{*}{$\begin{array}{l}\text { Obese men-BMI: } \\
30.0(1.0) \mathrm{kg} / \mathrm{m}^{2} ; \text { mean } \\
{[\text { Standard error of the }} \\
\text { mean }(\mathrm{SEM})]\end{array}$} & \multirow{4}{*}{$\begin{array}{c}96 \% \\
\text { white } \\
\text { (whole } \\
\text { sam- } \\
\text { ple) }\end{array}$} & \multirow{4}{*}{$62(44 / 18)$} & \multirow{4}{*}{$\begin{array}{c}61.0(1.0) / \\
60.0(1.0) \text {; mean } \\
\text { [Standard error of } \\
\text { the mean (SEM)] }\end{array}$} & \multicolumn{2}{|c|}{ Baseline period: Isoenergetic American Heart Association (AHA) phase I diet (3 months) } & Fasting glucose \\
\hline & & & & & & \multirow{2}{*}{$\begin{array}{l}\text { Diet-induced weight loss group: } \\
\text { Instructed to reduce energy intake by } 1260 \text { to } \\
2100 \mathrm{~kJ}(300 \text { to } 500 \text { kcal) per day. Goal was to } \\
\text { decrease body weight by more than } 10 \% \\
\text { during a } 9 \text { month period. Weekly group } \\
\text { weight loss sessions. Food records were } \\
\text { reviewed to ensure compliance to the diet. }\end{array}$} & \multirow{2}{*}{$\begin{array}{l}\text { Body weight maintenance group: } \\
\text { Instructed not to lose weight or change } \\
\text { their diets or level of physical activity. } \\
\text { Weekly } 1 \mathrm{~h} \text { dietary counselling meetings } \\
\text { to ensure compliance to the protocol. }\end{array}$} & Fasting insulin \\
\hline & & & & & & & & OGTT glucose $(2 \mathrm{~h})$ \\
\hline & & & & & & \multicolumn{2}{|c|}{ Intervention period: 36 weeks } & OGTT insulin (2 h) \\
\hline \multirow{6}{*}{$\begin{array}{l}\text { Joris PJ } \\
(2016)\end{array}$} & \multirow{6}{*}{$\begin{array}{l}\text { NA; } \\
\text { Netherlands }\end{array}$} & \multirow{6}{*}{$\begin{array}{l}\text { Abdominally obese } \\
\text { men-Waist } \\
\text { circumference: } 102-110 \\
\text { cm; range }\end{array}$} & \multirow{6}{*}{ Caucasian } & \multirow{6}{*}{$49(23 / 26)$} & \multirow{6}{*}{$\begin{array}{l}52.4(46.8-61.7) / \\
52.0(45.4-61.1) \\
\text { median (Q1-Q3) }\end{array}$} & \multicolumn{2}{|c|}{ Baseline period: Measurements of abdominally obese men were balanced (18 months) } & \multirow[b]{2}{*}{ Fasting glucose } \\
\hline & & & & & & \multirow{4}{*}{$\begin{array}{l}\text { Visited a research dietitian weekly ( } 12 \text { times } \\
\text { in totall and consumed a very-low-calorie } \\
\text { diet (VLCD) for }>=4 \text { weeks under strict } \\
\text { guidance. If the waist circumference was } \\
\text { still l } 102 \mathrm{~cm} \text { after } 4 \text { weeks, the VLCD was } \\
\text { continued for another week. The VLCD was } \\
\text { supplied in powder sachets that had to be } \\
\text { dissolved in water. Three sachets to be } \\
\text { consumed daily. Participants were allowed } \\
\text { to eat } 250 \mathrm{~g} \text { vegetables or fruit/day. After } \\
\text { the VLCDD period, subjects were prescribed a } \\
\text { mixed, solid, calorie-restricted diet. }\end{array}$} & \multirow[t]{4}{*}{$\begin{array}{l}\text { Body weight maintenance group: } \\
\text { Maintained their habitual diet, physical } \\
\text { activity levels, and use of alcohol } \\
\text { throughout the total study period. Visited } \\
\text { a research dietitian on } 2 \text { occasions. }\end{array}$} & \\
\hline & & & & & & & & Fasting insulin \\
\hline & & & & & & & & C-peptide \\
\hline & & & & & & & & HOMA_IR \\
\hline & & & & & & $\begin{array}{l}\text { Intervention period: } 8 \text { weeks (a calorie-re } \\
\text { circumference }<102 \mathrm{~cm} \text { followed by a }\end{array}$ & $\begin{array}{l}\text { tricted diet for } 6 \text { weeks to obtain a waist } \\
\text { eight-maintenance period of } 2 \text { weeks) }\end{array}$ & HOMAA-IR \\
\hline
\end{tabular}


Table 1. Cont.

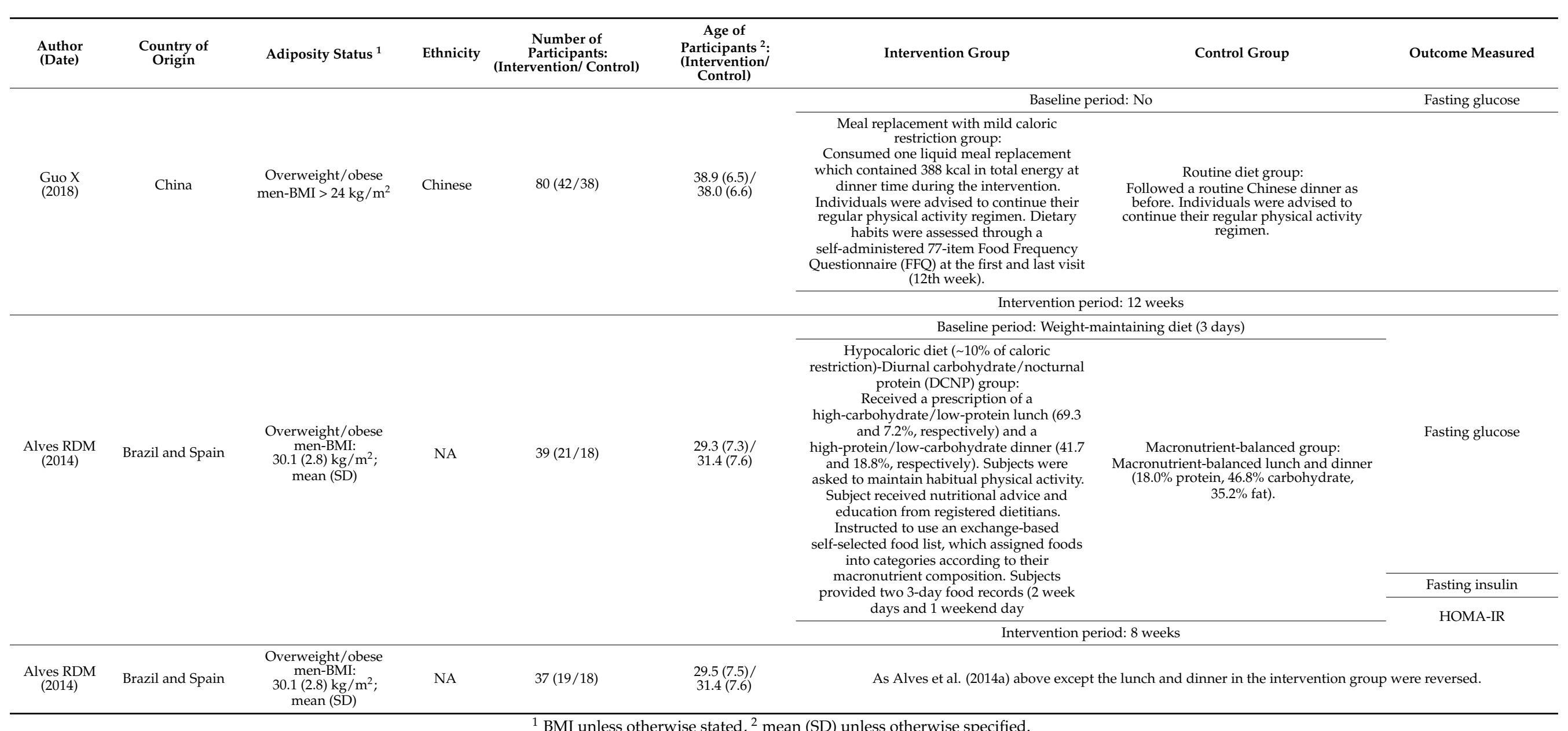

${ }^{1}$ BMI unless otherwise stated, ${ }^{2}$ mean (SD) unless otherwise specified. 
Six of the seven studies measured fasting circulating glucose levels as the outcome, five measured fasting circulating insulin, two measured HOMA-IR, two measured both circulating glucose and insulin following a glucose tolerance test, one study measured glucose disposal rate and another one study measured circulating C-peptide.

A further 11 potential studies of interventions to reduce body fatness with biomarkers of insulin as outcomes were identified by our searches, but were subsequently excluded (Table S1) because they were not randomised, or they did not include a placebo control group, or there was no separate analysis for men, or the study did not measure the biomarkers we were interested in, or the study was of men undergoing resistance training or a large proportion (or all) of participants were known to have pre-existing prostate cancer or metabolic syndrome.

Risk of Bias

For our body fatness-insulin association studies, we present one risk-of-bias assessment per study, because each outcome measure was based on a blood sample collected in the same manner and processed in the same laboratory. For the study by Alves et al. [32], we assessed risk of bias for each of two interventions, both aimed to reduce body weight by prescribing either a) high-carbohydrate/low-protein lunch and a highprotein/low-carbohydrate dinner or b) a high-protein/low-carbohydrate lunch and a high-carbohydrate/low-protein dinner. All seven studies of body fatness and insulin were rated as having some concerns or high risk of bias and four of these were rated as being at a high risk of bias (Table S2). The study by Alves et al. [32] was rated as high risk of bias for both interventions. Studies were rated as high risk of bias mainly due to the high number of participants dropping out within the study and these individuals not being accounted for in the analysis.

\subsection{Effect of Reduction in Body Fatness on Biomarkers of Insulin Sensitivity}

All studies included in this systematic review achieved their aim of reducing body fatness except the study by Alves et al. [32]. All those studies in which the intervention resulted in a reduction in body fatness observed either a greater reduction or a smaller increase in insulin and glucose levels in the intervention group when comparing preand post-intervention levels (Table S3 and Figures 3-5). The one study which achieved a reduction in body fatness, and which measured HOMA-IR [34], found a 37\% reduction in levels of this biomarker post-intervention in the treatment group (from 2.64 pre-intervention to 1.67 post-intervention) but no change was seen in the control group (2.90 to 2.96), pvalue for difference in pre-post-intervention change between the two groups was 0.01 . Similarly, the one study to have measured C-peptide found a reduction in this biomarker following body fatness reduction in the intervention group (1.59 to $1.26 \mathrm{ng} / \mathrm{L}$ ) but not in the control group (1.75 to $1.76 \mathrm{ng} / \mathrm{L}), p=0.05$. Ross et al. [37] was the only study to have measured glucose and insulin ina glucose tolerance test and to have measured glucose disposal rate following an intervention to reduce body fatness in men. This study found evidence of a faster glucose disposal rate among men in the body fatness reduction group after intervention compared with those in the control group (glucose clearance changed after intervention from 13.0 to $18.6 \mathrm{mg} / \mathrm{kg}$ muscle per minute in the intervention group compared with 15.4 to $14.4 \mathrm{mg} / \mathrm{kg}$ muscle per minute, $\mathrm{p}$ value for-difference between control and intervention group $=0.02$ ). 


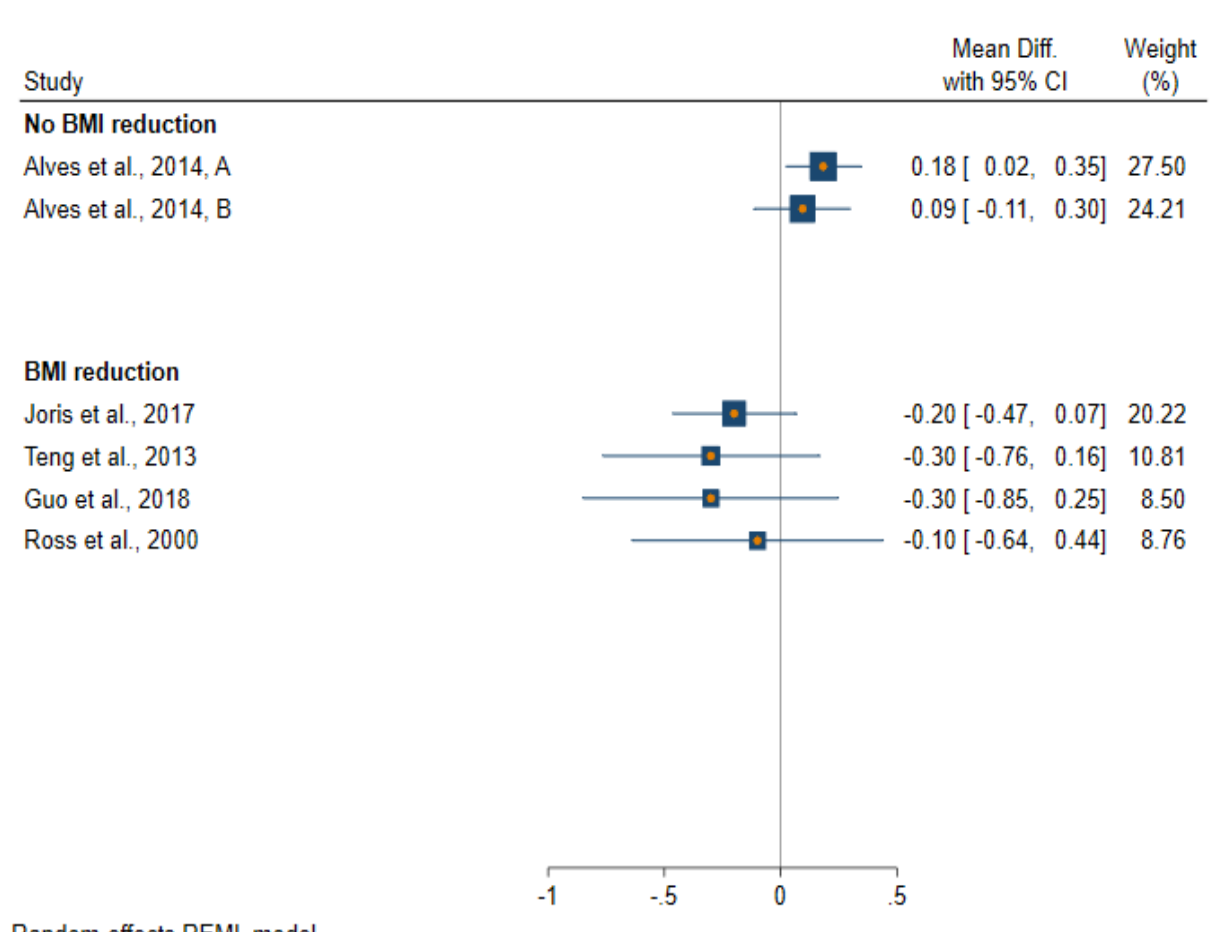

Random-effects REML model

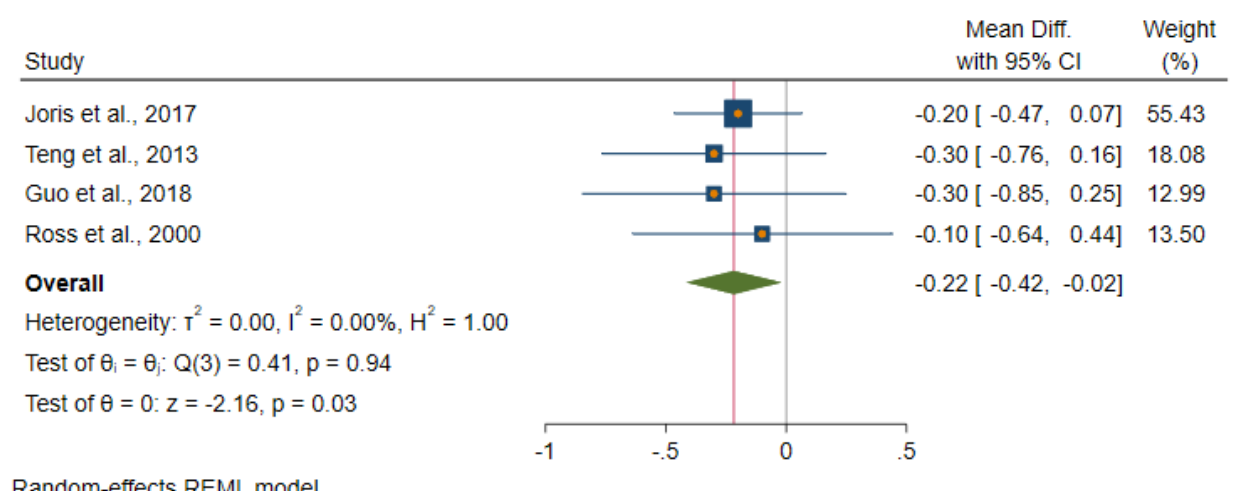

Figure 3. Forest plot of studies which evaluated an effect of a reduction in body fatness on fasting glucose levels.

\section{Grade Assessment}

The GRADE assessment of certainty in the evidence was downgraded by two points from high certainty to low certainty due to: the risk of bias in individual studies (all studies were at either high risk of bias or had some concerns of bias) (1 level); imprecision due to the small number of studies ( 0.5 level) and small number of included individuals in each study; and ( 0.5 level) reporting bias because these biomarkers were secondary outcomes within the RCTs we included and it is possible that other RCTs have not published data on these outcomes. We did not downgrade due to indirectness of evidence because all studies were conducted in adult men, who were recruited from the general population. We also did not downgrade the evidence due to heterogeneity as there was no evidence of this after excluding one study which did not observe a reduction in body fatness following their intervention [32]. 


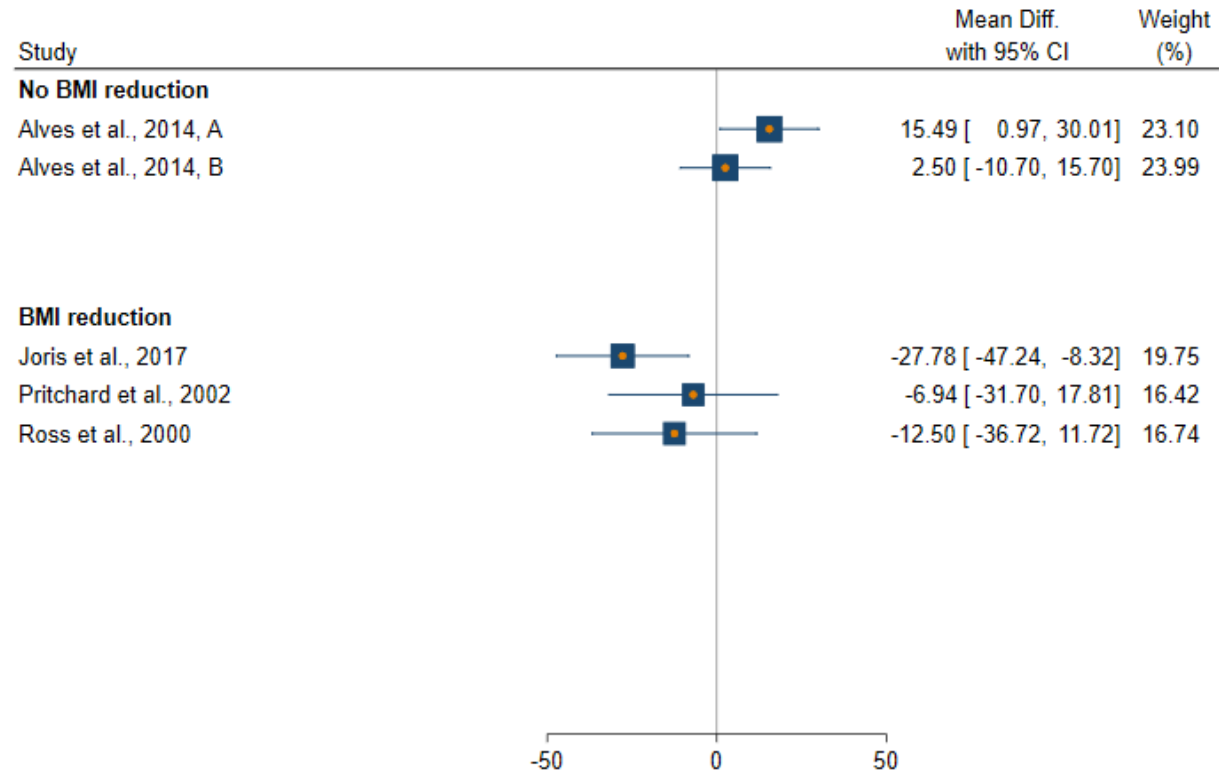

Random-effects REML model

Mean Diff. Weight

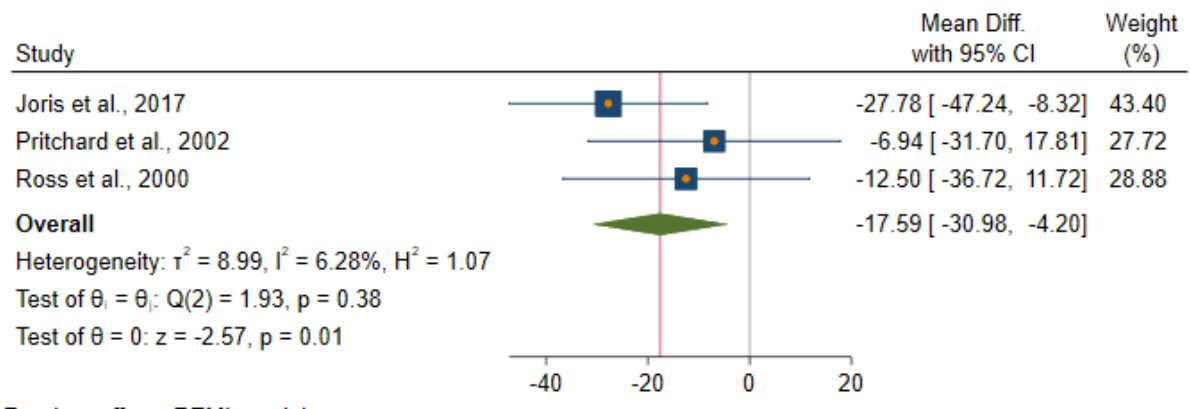

Random-effects REML model

Figure 4. Forest plot of studies which evaluated an effect of a reduction in body fatness on fasting insulin levels.

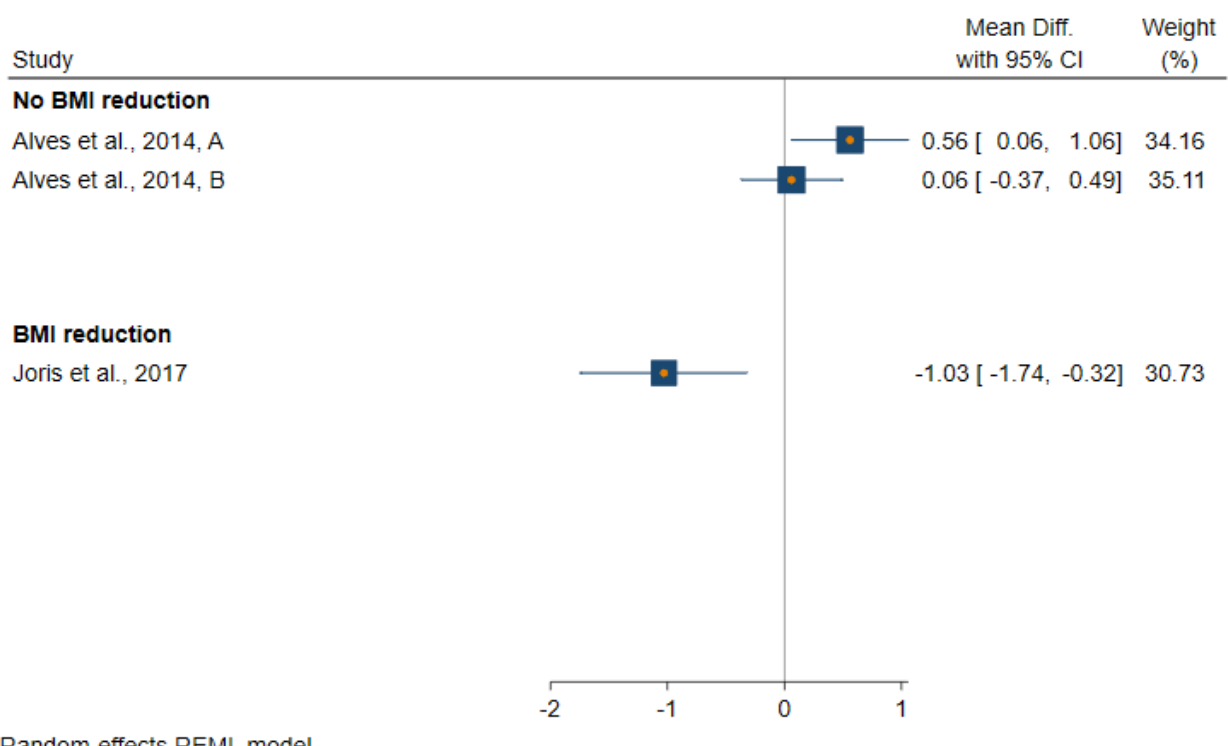

Figure 5. Forest plot of studies which evaluated an effect of a reduction in body fatness on HOMA-IR levels. 


\subsection{Insulin-Prostate Association Cancer Studies}

There were six prospective observational studies [39-44] which investigated whether biomarkers of circulating insulin were associated with prostate cancer risk at follow-up (Table 2). The studies were carried out in the USA (four studies), Iceland (1 study) and Finland (1 study), and ranged in size from 100 to 2554 men with PCa. Two of these studies measured C-peptide only, one study measured fasting glucose, another glucose tolerance, one measured fasting glucose and $\mathrm{HbA} 1 \mathrm{c}$ and the final study measured fasting glucose, fasting insulin, the molar ratio insulin/glucose and HOMA-IR. All studies investigated the association of insulin biomarkers on total prostate cancer risk and advanced PCa, and all but one study [41] investigated localised prostate cancer.

We excluded nine studies which did not adjust their insulin biomarker-PCa results by BMI (Table S4). The reason for this is that we were interested in the effect of body fatness on PCa only via the insulin pathway. We also excluded a further 7 studies which did not have at least 2 years follow-up between exposure and outcome measurement, 1 study which did not present data relevant to our research question, and another study which included participants who did not mean our eligibility criteria (Table S4).

Risk of Bias

We assessed risk of bias in each study separately for each insulin biomarker exposure and each separate outcome (total PCa, localised PCa) (Table S5). For every study and every assessment, there were some concerns relating to domain 1 -confounding, due to the studies all being observational. There were also some concerns for two studies $[41,44]$ in relation to domain 5-missing data for the outcome of total PCa. There was a high risk of bias for the same domain (5) for the advanced and high-grade PCa outcomes in the study by Dickerman et al. [41].

\subsection{Associations between Biomarkers of Insulin Sensitivity and PCa Risk}

The results for the association between insulin and PCa risk from the studies included in our review are given in Table S6. For all exposure-outcome pairs, except fasting glucose, there were too few studies investigating the same exposure and outcome to perform metaanalyses so the results are described below in text and in the Albatross plot in Figure 6.

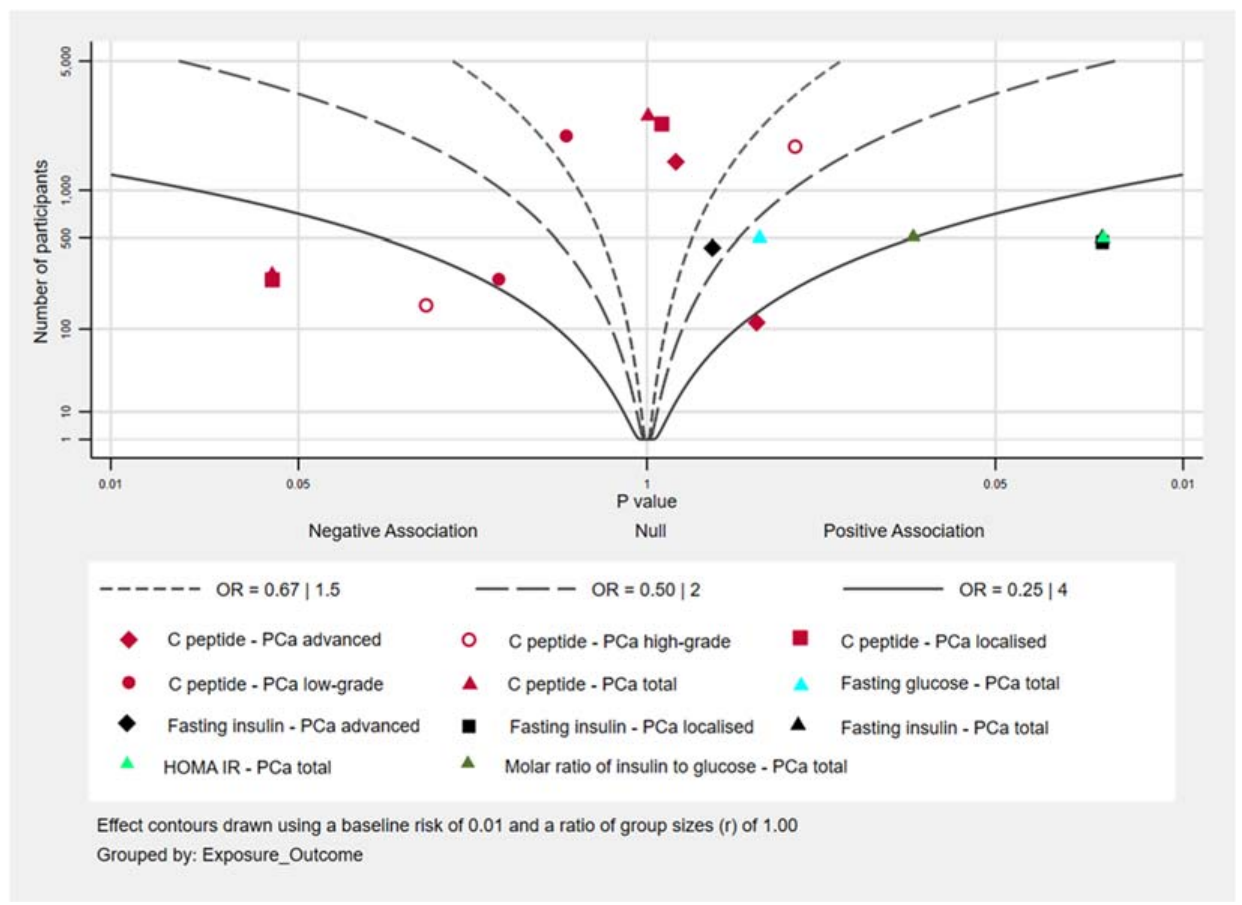

Figure 6. Albatross plot showing effect of insulin biomarkers on prostate cancer risk; each point on the figure represents a single analysis in an individual study. 
Table 2. Characteristics of included studies (insulin-PCa association set of studies).

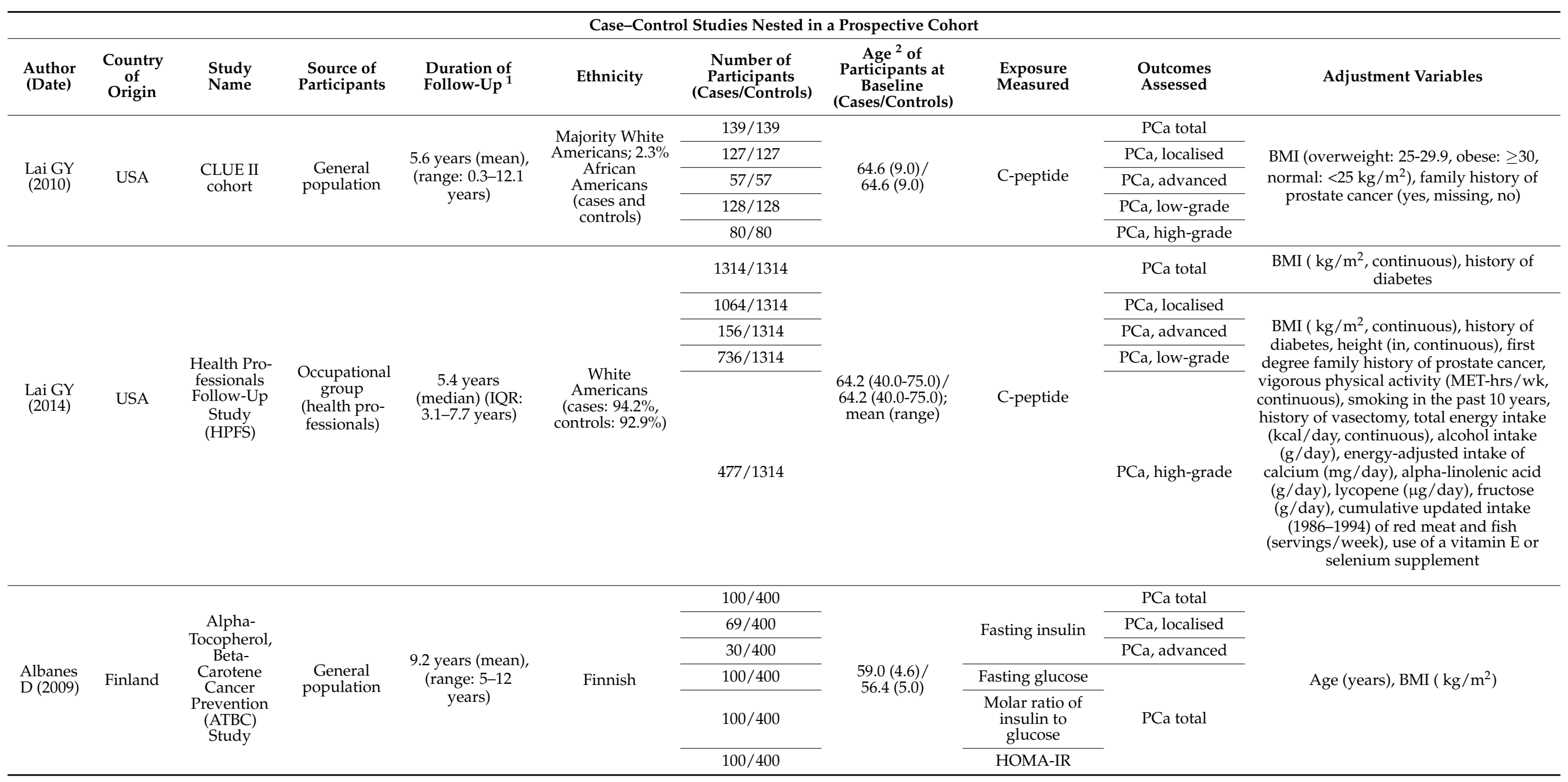


Table 2. Cont.

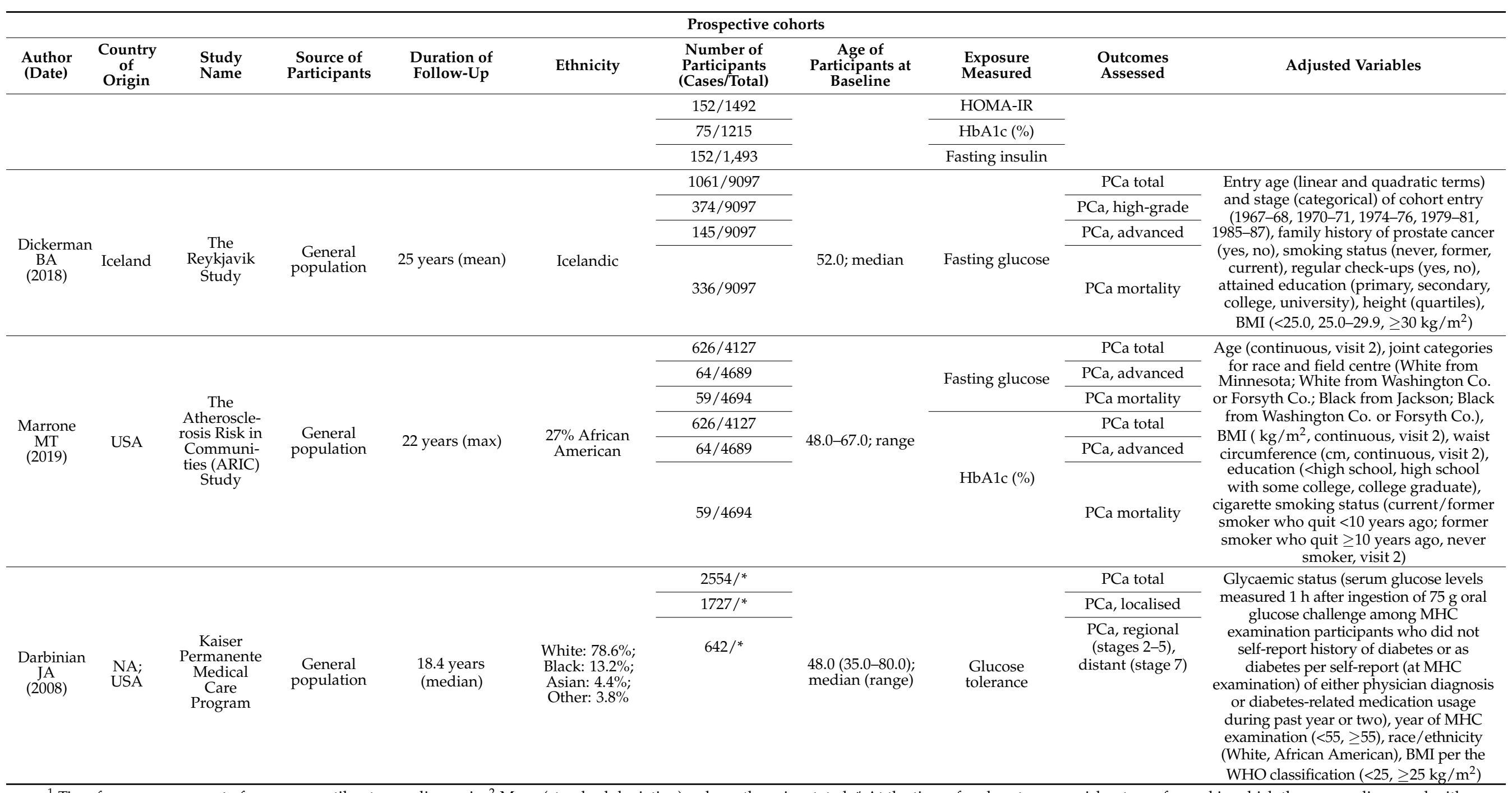

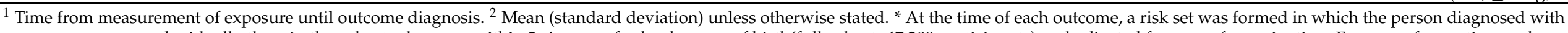

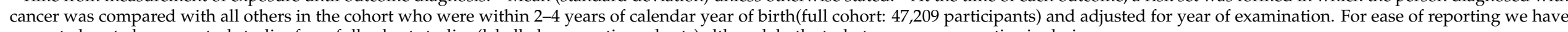
separated nested case-control studies from full cohort studies (labelled prospective cohorts) although both study types are prospective in design. 


\section{C-Peptide}

In a small study (139 cases) published in 2010 by Lai et al. [42], high C-peptide levels were associated with a lower risk of PCa. However, in a study published in 2014 by the same authors [43], there was little evidence of an association.

Fasting Glucose and Glucose Tolerance

Three studies $[39,41,44]$ investigated the association between fasting blood glucose levels and later risk of total and advanced PCa. The largest of these studies [41] found weak evidence that high blood glucose levels were associated with a reduced PCa risk and an effect in the same direction for advanced $\mathrm{PCa}$, high-grade prostate cancer and $\mathrm{PCa}$ mortality, albeit with wide confidence intervals. Another study [44] found little evidence of an association with overall PCa risk and a high risk of advanced PCa and PCa mortality associated with higher blood glucose levels. The last of the three studies [39] consisted of 100 cases and did not add to the evidence base because the confidence intervals for the associations investigated in this study were very wide.

Darbinian et al. [40] investigated the effect of glucose tolerance and found that those with higher glucose levels one hour after a glucose challenge had a lower PCa risk.

HOMA-IR, Insulin and Molar Ratio

In a small study by Albanes et al. [39], the authors investigated the effect of fasting insulin, HOMA-IR and the molar ratio of insulin to glucose on PCa risk. They found that higher fasting insulin, higher HOMA-IR and a higher molar ratio of insulin to glucose were all associated with increased PCa risk, although the latter association had wider confidence intervals.

GRADE Assessment

We downgraded the evidence on insulin signalling and prostate cancer to very low certainty due to: risk of bias, which was at least moderate for all studies; heterogeneity between the studies; and imprecision (1 level for each).

\section{Discussion}

\subsection{Overall Findings}

We found very few studies $(n=7)$ which investigated the effect of a reduction in body fatness in males on biomarkers of insulin sensitivity. Of the eligible studies we identified, one did not observe a reduction in body fatness despite having implemented a calorierestricted dietary intervention [32]. This same study [32] also observed that the effect of the intervention on blood biomarker levels was different to that in other studies. However, the studies which observed a reduction in body fatness as a result of their intervention, also found a subsequent decrease in blood glucose, insulin and C-peptide [33-38]. They showed that all indicators of insulin sensitivity improved following interventions to reduce body fatness.

We excluded several potentially eligible studies either because they did not carry out randomisation of intervention, they did not present their analysis separately for males, or because they were performed in men who already had impaired insulin sensitivity. The studies which were included in our review were assessed as having at least some concerns in relation to risk of bias.

It was difficult to draw conclusions on the effect of insulin sensitivity on PCa risk from the few studies we were able to include in our systematic review. With the exception of fasting glucose, there were only one or two studies investigating each biomarker and the evidence was heterogeneous. We excluded several studies either because they did not allow at least a two-year lag between exposure measurement and PCa or did not adjust their insulin biomarker-PCa association by BMI. A lag period is important to avoid reverse causation particularly in relation to PCa risk which has a long latency period. The hypothesis we were investigating in this review was whether body fatness affected $\mathrm{PCa}$ risk via insulin signalling. If we had included studies which did not adjust by BMI, we 
would be addressing the question of whether BMI was associated with PCa risk since BMI is so strongly correlated with biomarkers of insulin.

\subsection{Strengths and Limitations of Our Review}

We used methodology that we have previously developed with WCRF to systematically investigate the evidence for specific mechanisms between exposures and cancer outcomes [12]. We carried out a thorough search and employed inclusion criteria which meant that only those studies which most directly addressed our research question were included (i.e., we only included RCTs of interventions to reduce body fatness in men as our research question was whether reducing body fatness impacts on PCa risk via the insulin signalling pathway). We also sought to minimise bias by excluding studies with insufficient follow-up. We carried out risk of bias assessments on all included studies to determine the reliability of the evidence. In addition, four authors jointly carried out GRADE assessments to judge the level of certainty of the overall evidence.

However, we found that the overall certainty of the evidence was low for the effect of reducing body fatness on biomarkers of insulin sensitivity in men and very low for the effect of insulin sensitivity on PCa risk. Despite there being a wealth of evidence on the association between body fatness and insulin signalling (our searches found more than 15,478 manuscripts), there was very little evidence which met our inclusion criteria, or which directly addressed the question of whether reducing body fatness in adult men could impact this mechanistic pathway. Two important reasons for investigating mechanisms between exposures and cancer is to determine whether the association is causal or not, and to identify potential targets for intervention. The approach we have taken is more cost effective and will provide answers more quickly than a trial of interventions to reduce body fatness with cancer risk as the outcome. However, it does depend on evidence relating to the intermediate phenotype being available.

\section{Conclusions}

Our review has highlighted that insulin sensitivity is a potential mechanistic pathway via which body fatness could impact on PCa risk and has suggested that reducing body fatness may improve insulin sensitivity. However, the evidence linking insulin sensitivity to prostate cancer risk is inconclusive due to a lack of high-quality studies investigating this. Therefore, much more research is needed in this area before any firm conclusions on this mechanistic pathway can be drawn.

Supplementary Materials: The following are available online at https:/ / www.mdpi.com/article/ 10.3390/metabo11110726/s1, Figure S1: Inclusion/exclusion criteria applied to potentially eligible insulin-prostate cancer studies, Table S1: Reasons for exclusion for the Body-fatness-Insulin set of studies (Randomized controlled trials), Table S2: Risk of bias assessment for body fatness-insulin studies per domain and overall using the Robins-I tool ), Table S3:Converted and calculated data (Body-Fatness-Insulin set of studies), Table S4: Reasons for exclusion for the Insulin-PCa set of studies, Table S5: Risk of bias assessment per domain and overall for the insulin-prostate cancer study, using the Robins-E risk of bias tool, Table S6: Descriptive results as reported by the studies (Insulin-PCa set of studies), Table S7: Prostate cancer outcome categories by study.

Author Contributions: R.J. contributed to the design of the study, carried out the searches, screened the output from the searches and wrote the first draft of the introduction and methods. O.D. contributed to the study design and decisions on study inclusion, extracted data from each study, generated the tables and figures, and contributed to GRADE assessments and writing this paper. R.M.M. contributed to all aspects of the study design, interpretation of results, GRADE assessments and to the writing of this paper. C.M.P. provided expert knowledge on insulin sensitivity, advised on search terms, and contributed to the interpretation of results and writing this paper. C.K. and L.M. helped to screen the studies for inclusion and edited this paper. S.B. extracted data from included studies and contributed to decisions on study methodology. J.P.T.H. and S.J.L. conceptualised the study, designed the study methodology, supervised R.J. and O.D., helped to interpret the results, led 
the GRADE assessments and contributed to writing this paper. All authors have read and agreed to the published version of the manuscript.

Funding: This review was funded by the World Cancer Research Fund International (grant number: WCRF 2015/1421). R.M.M., C.P. and S.J.L. were supported by a Cancer Research UK (C18281/A29019) programme grant (the Integrative Cancer Epidemiology Programme). J.P.T.H., R.M.M. and S.J.L. were supported by the NIHR Biomedical Research Centre at University Hospitals Bristol and Weston NHS Foundation Trust and the University of Bristol. J.P.T.H. was supported by the NIHR Applied Research Collaboration West at University Hospitals Bristol and Weston NHS Foundation Trust. The views expressed are those of the author(s) and not necessarily those of the WCRF, CRUK, NIHR or the Department of Health and Social Care.

Data Availability Statement: The data presented in this study are taken from published sources and are available in the article and supplementary material.

Conflicts of Interest: The authors declare no conflict of interest.

\section{References}

1. Rawla, P. Epidemiology of Prostate Cancer. World J. Oncol. 2019, 10, 63-89. [CrossRef] [PubMed]

2. Bray, F.; Me, J.F.; Soerjomataram, I.; Siegel, R.L.; Torre, L.A.; Jemal, A. Global cancer statistics 2018: GLOBOCAN estimates of incidence and mortality worldwide for 36 cancers in 185 countries. CA Cancer J. Clin. 2018, 68, 394-424. [CrossRef]

3. Hsing, A.W.; Chokkalingam, A.P. Prostate cancer epidemiology. Front. Biosci. J. Virtual Libr. 2006, 11, 1388-1413. [CrossRef]

4. Byers, T.; Sedjo, R.L. Body fatness as a cause of cancer: Epidemiologic clues to biologic mechanisms. Endocr.-Relat. Cancer 2015, 22, R125-R134. [CrossRef]

5. Lauby-Secretan, B.; Scoccianti, C.; Loomis, D.; Grosse, Y.; Bianchini, F.; Straif, K. Body Fatness and Cancer-Viewpoint of the IARC Working Group. N. Engl. J. Med. 2016, 375, 794-798. [CrossRef]

6. Pearson-Stuttard, J.; Zhou, B.; Kontis, V.; Bentham, J.; Gunter, M.J.; Ezzati, M. Worldwide burden of cancer attributable to diabetes and high body-mass index: A comparative risk assessment. Lancet Diabetes Endocrinol. 2018, 6, e6-e15. [CrossRef]

7. Cao, Y.; Ma, J. Body Mass Index, Prostate Cancer-Specific Mortality, and Biochemical Recurrence: A Systematic Review and Meta-analysis. Cancer Prev. Res. 2011, 4, 486-501. [CrossRef]

8. Bassett, J.K.; Severi, G.; Baglietto, L.; MacInnis, R.J.; Hoang, H.N.; Hopper, J.L. English, D.R., \& Giles, G.G.. Weight change and prostate cancer incidence and mortality. Int. J. Cancer 2012, 131, 1711-1719.

9. Strom, S.S.; Wang, X.; Pettaway, C.A.; Logothetis, C.J.; Yamamura, Y.; Do, K.A.; Babaian, R.J.; Troncoso, P. Obesity, weight gain, and risk of bio-chemical failure among prostate cancer patients following prostatectomy. Clin. Cancer Res. 2005, 11, 6889-6894.

10. MacInnis, R.J.; English, D. Body size and composition and prostate cancer risk: Systematic review and meta-regression analysis. Cancer Causes Control. 2006, 17, 989-1003. [CrossRef]

11. NCD Risk Factor Collaboration (NCD-RisC). Trends in adult body-mass index in 200 countries from 1975 to 2014 : A pooled analysis of 1698 population-based measurement studies with 19.2 million participants. Lancet 2016, 387, 1377-1396. [CrossRef]

12. Lewis, S.J.; Gardner, M.; Higgins, J.; Holly, J.M.; Gaunt, T.R.; Perks, C.M.; Turner, S.D.; Rinaldi, S.; Thomas, S.; Harrison, S.; et al. Developing the WCRF International/University of Bristol Methodology for Identifying and Carrying Out Systematic Reviews of Mechanisms of Exposure-Cancer Associations. Cancer Epidemiol. Biomark. Prev. 2017, 26, 1667-1675. [CrossRef]

13. Kaaks, R.; Lukanova, A. Energy balance and cancer: The role of insulin and insulin-like growth factor-I. Proc. Nutr. Soc. 2001, 60, 91-106. [CrossRef]

14. Kahn, B.B.; Flier, J.S. Obesity and insulin resistance. J. Clin. Investig. 2000, 106, 473-481. [CrossRef]

15. Everson, S.; Glodberg, D.E.; Helmrich, S.P.; Lakka, T.; Lynch, J.W.; Kaplan, G.A.; Salonen, J.T. Weight Gain and the Risk of Developing Insulin Resistance Syndrome. Diabetes Care 1998, 21, 1637-1643. [CrossRef]

16. Chang, Y.; Sung, E.; Yun, K.E.; Jung, H.-S.; Kim, C.-W.; Kwon, M.-J.; Cho, S.-I.; Ryu, S. Weight Change as a Predictor of Incidence and Remission of Insulin Resistance. PLoS ONE 2013, 8, e63690. [CrossRef]

17. Arcidiacono, B.; Iiritano, S.; Nocera, A.; Possidente, K.; Nevolo, M.T.; Ventura, V.; Foti, D.; Chiefari, E.; Brunetti, A. Insulin Resistance and Cancer Risk: An Overview of the Pathogenetic Mechanisms. Exp. Diabetes Res. 2012, 2012, 789174. [CrossRef]

18. van Dam, R.M. The epidemiology of lifestyle and risk for type 2 diabetes. Eur. J. Epidemiol. 2003, 18, 1115-1125. [CrossRef] [PubMed]

19. Wells, J.C.K. Body composition and susceptibility to type 2 diabetes: An evolutionary perspective. Eur. J. Clin. Nutr. 2017, 71, 881-889. [CrossRef] [PubMed]

20. Fogelholm, M. Physical activity, fitness and fatness: Relations to mortality, morbidity and disease risk factors. A systematic review. Obes. Rev. 2010, 11, 202-221. [CrossRef] [PubMed]

21. Saboori, S.; Rad, E.Y.; Birjandi, M.; Mohiti, S.; Falahi, E. Serum insulin level, HOMA-IR and prostate cancer risk: A systematic review and meta-analysis. Diabetes Metab. Syndr. Clin. Res. Rev. 2019, 13, 110-115. [CrossRef] [PubMed]

22. Bonovas, S.; Filioussi, K.; Tsantes, A. Diabetes mellitus and risk of prostate cancer: A meta-analysis. Diabetologia 2004, 47, 1071-1078. [CrossRef] 
23. Kasper, J.S.; Giovannucci, E. A meta-analysis of diabetes mellitus and the risk of prostate cancer. Cancer Epidemiol. Biomark. Prev. 2006, 15, 2056-2062. [CrossRef]

24. Whitburn, J.; Edwards, C.; Sooriakumaran, P. Metformin and Prostate Cancer: A New Role for an Old Drug. Curr. Urol. Rep. 2017, 18, 46. [CrossRef]

25. International Agency for Research on Cancer. Preamble for Primary Interventions. IARC Handbook of Cancer Prevention 2019. Available online: http:/ / handbooks.iarc.fr/preambles/index.php (accessed on 25 May 2021).

26. Basaria, S. Androgen Deprivation Therapy, Insulin Resistance, and Cardiovascular Mortality: An Inconvenient Truth. J. Androl. 2008, 29, 534-539. [CrossRef] [PubMed]

27. Egger, M.; Smith, G.D.; Schneider, M.; Minder, C. Bias in meta-analysis detected by a simple, graphical test. BMJ 1997, 315, 629-634. [CrossRef]

28. Harrison, S.; Jones, H.; Martin, R.; Lewis, S.J.; Higgins, J. The albatross plot: A novel graphical tool for presenting results of diversely reported studies in a systematic review. Res. Synth. Methods 2017, 8, 281-289. [CrossRef]

29. Sterne, J.A.C.; Savović, J.; Page, M.; Elbers, R.G.; Blencowe, N.; Boutron, I.; Cates, C.; Cheng, H.-Y.; Corbett, M.S.; Eldridge, S.M.; et al. RoB 2: A revised tool for assessing risk of bias in randomised trials. BMJ 2019, 366, 14898. [CrossRef]

30. Guyatt, G.H.; Oxman, A.D.; Vist, G.E.; Kunz, R.; Falck-Ytter, Y.; Alonso-Coello, P.; Schünemann, H.J. GRADE: An emerging consensus on rating quality of evidence and strength of recommendations. BMJ 2008, 336, 924-926. [CrossRef]

31. Schünemann, H.J.; Cuello, C.; Akl, E.A.; Mustafa, R.A.; Meerpohl, J.J.; Thayer, K.; Morgan, R.L.; Gartlehner, G.; Kunz, R.; Katikireddi, S.V.; et al. GRADE guidelines: 18. How ROBINS-I and other tools to assess risk of bias in nonrandomized studies should be used to rate the certainty of a body of evidence. J. Clin. Epidemiol. 2019, 111, 105-114. [CrossRef] [PubMed]

32. Alves, R.D.M.; De Oliveira, F.C.E.; Hermsdorff, H.H.M.; Abete, I.; Zulet, M.A.; Martínez, J.A.; Bressan, J. Eating carbohydrate mostly at lunch and protein mostly at dinner within a covert hypocaloric diet influences morning glucose homeostasis in overweight/obese men. Eur. J. Nutr. 2014, 53, 49-60. [CrossRef] [PubMed]

33. Guo, X.; Xu, Y.; He, H.; Cai, H.; Zhang, J.; Li, Y.; Yan, X.; Zhang, M.; Zhang, N.; Maddela, R.L.; et al. Effects of a Meal Replacement on Body Composition and Metabolic Parameters among Subjects with Overweight or Obesity. J. Obes. 2018, 2018, 2837367. [CrossRef] [PubMed]

34. Joris, P.J.; Plat, J.; Kusters, Y.H.; Houben, A.J.; DA Stehouwer, C.; Schalkwijk, C.G.; Mensink, R.P. Diet-induced weight loss improves not only cardiometabolic risk markers but also markers of vascular function: A randomized controlled trial in abdominally obese men. Am. J. Clin. Nutr. 2017, 105, 23-31. [CrossRef]

35. Katzel, L.I.; Bleecker, E.R.; Rogus, E.M.; Goldberg, A.P. Sequential effects of arobic exercise training and weight loss on risk factors for coronary disease in healthy, obese middle-aged and older men. Metabolism 1997, 46, 1441-1447. [CrossRef]

36. Pritchard, J.E.; Nowson, C.A.; Billington, T.; Wark, J.D. Benefits of a year-long workplace weight loss program on cardiovascular risk factors. Nutr. Diet. 2002, 59, 87-96.

37. Ross, R.; Dagnone, D.; Jones, P.J.; Smith, H.; Paddags, A.; Hudson, R.; Janssen, I. Reduction in Obesity and Related Comorbid Conditions after Diet-Induced Weight Loss or Exercise-Induced Weight Loss in Men. Ann. Intern. Med. 2000, 133, 92-103. [CrossRef]

38. Teng, N.I.M.F.; Shahar, S.; Rajab, N.F.; Manaf, Z.A.; Johari, M.H.; Ngah, W.Z.W. Improvement of metabolic parameters in healthy older adult men following a fasting calorie restriction intervention. Aging Male 2013, 16, 177-183. [CrossRef]

39. Albanes, D.; Weinstein, S.J.; Wright, M.; Männistö, S.; Limburg, P.J.; Snyder, K.; Virtamo, J. Serum Insulin, Glucose, Indices of Insulin Resistance, and Risk of Prostate Cancer. J. Natl. Cancer Inst. 2009, 101, 1272-1279. [CrossRef] [PubMed]

40. Darbinian, J.A.; Ferrara, A.; Van Den Eeden, S.K.; Quesenberry, C.P.; Fireman, B.; Habel, L. Glycemic Status and Risk of Prostate Cancer. Cancer Epidemiol. Biomark. Prev. 2008, 17, 628-635. [CrossRef]

41. Dickerman, B.A.; Torfadottir, J.E.; Valdimarsdottir, U.A.; Wilson, K.M.; Steingrimsdottir, L.; Aspelund, T.; Batista, J.L.; Fall, K.; Giovannucci, E.; Sigurdardottir, L.G.; et al. Midlife metabolic factors and prostate cancer risk in later life. Int. J. Cancer 2018, 142, 1166-1173. [CrossRef]

42. Lai, G.Y.; Helzlsouer, K.J.; Clipp, S.L.; Rifai, N.; Platz, E.A. Association between C-Peptide Concentration and Prostate Cancer Incidence in the CLUE II Cohort Study. Cancer Prev. Res. 2010, 3, 1334-1341. [CrossRef] [PubMed]

43. Lai, G.Y.; Giovannucci, E.L.; Pollak, M.N.; Peskoe, S.B.; Stampfer, M.J.; Willett, W.C.; Platz, E.A. Association of C-peptide and leptin with prostate cancer incidence in the Health Professionals Follow-up Study. Cancer Causes Control. 2014, 25, 625-632. [CrossRef] [PubMed]

44. Marrone, M.T.; Selvin, E.; Barber, J.R.; Platz, E.A.; Joshu, C.E. Hyperglycemia, Classified with Multiple Biomarkers Simultaneously in Men without Diabetes, and Risk of Fatal Prostate Cancer. Cancer Prev. Res. 2019, 12, 103-112. [CrossRef] [PubMed] 